\title{
Exposure to secondhand smoke in Iranian pregnant women at home and the related factors
}

\author{
Seyed Saeed Mazloomy Mahmoodabad', Zohreh Karimiankakolaki', Ashraf Kazemi², Nastaran Keshavarz Mohammadi, \\ Hossein Fallahzadeh ${ }^{4}$
}

\begin{abstract}
INTRODUCTION Fetus health is of high importance in pregnant women and exposure to secondhand smoke (SHS) endangers maternal and fetal health. Therefore, in this study we examined the prevalence of exposure to SHS in pregnant women at home and the related factors.

METHODS This cross-sectional study was conducted with 255 pregnant women who were referred to the Isfahan health care center from July to September 2018. A questionnaire that was designed by the research team was applied to collect data about the participants' prevalence of exposure, attitude-emotional dimension, perceived susceptibility, perceived severity, and perceived barriers. The questionnaire used was self-administered. The validity and reliability of the questionnaire were confirmed by a panel of experts. Cronbach's alpha of attitude-emotional dimension, perceived susceptibility, perceived severity, and perceived barriers were also calculated as $0.81,0.91,0.92$, and 0.89 , respectively. Statistically significant differences were examined using chi-squared test and Mann-Whitney test.
\end{abstract}

RESULTS We found that the prevalence of exposure to SHS in pregnant women was $23.1 \%$. The age of the husband ( $\mathrm{p}=0.041$ ), education level of the smoking husband $(p=0.005)$, the education level of the pregnant woman $(p=0.002)$, employment status of husband $(p=0.010)$, and whether the pregnancy was planned $(p=0.010)$ had significant association with the participant prevalence of exposure to SHS. Thus, older age of husbands, lower education levels of husbands and wives, unwanted pregnancies, and unemployment of husbands resulted in higher exposure to SHS. The mean scores of knowledge and perceptions were lower in women exposed to smoke than in non-exposed women $(\mathrm{p}<0.05)$.

CONCLUSIONS The rate of SHS exposure was high in pregnant women. The knowledge and perception scores of exposed women to SHS were lower than those of non-exposed women. Low levels of education of husbands and women, unemployment and higher age of husbands, and unwanted pregnancies were considered as health risk factors. Therefore, effective training programs should be designed to educate pregnant women and their husbands.

\begin{abstract}
AFFILIATION
1 Social Determinants of Health Research Center, Department of Health Education and Promotion, School of Public Health, Shahid Sadoughi University of Medical Sciences, Yazd, Iran

2 Department of Reproductive Health, School of Nursing and Midwifery, Isfahan University of Medical Sciences, Isfahan, Iran 3 School of Health and Safety, Shahid Beheshti University of Medical Sciences, Tehran, Iran 4 Department of Biostatistics and Epidemiology, Shahid Sadoughi University of Medical Sciences, Yazd, Iran
\end{abstract}

\section{CORRESPONDENCE TO}

Zohreh Karimiankakolaki. Health Education and Promotion, Department of Health Education and Promotion, School of health, Shahid Sadoughi University of Medical Sciences, Yazd, Iran. E-mail: zohrehkarimian68@yahoo.com ORCID ID: https://orcid.org/00000002-5946-0955

\section{KEYWORDS}

health belief, pregnant women, exposure to smoke, smoking husbands

Received: 1 October 2018

Revised: 3 January 2019

Accepted: 15 February 2019

\section{INTRODUCTION}

Habits of smoking are frequently observed among various social groups with the rates of men smoking in developing and developed countries being $50 \%$ and $35 \%$, respectively ${ }^{1}$. Non-smokers are exposed to health hazards by breathing the SHS from smokers ${ }^{2,3}$. 
Exposure to smoke includes breathing smoke emanating from burning cigarettes and indirectly from exhaled smoke $\mathrm{e}^{4,5}$. The exposure to SHS causes several severe complications in pregnant women such as preterm labor ${ }^{6-10}$, rupture of membranes ${ }^{11}$, increased probability of a cesarean operation ${ }^{7}$, decreased growth of fetus, delayed intrauterine growth $^{1,6,10}$, low birth weight of fetus ${ }^{6,8-10}$, distressed fetus ${ }^{8,9}$, small embryo for the gestational age ${ }^{7}$, sudden infant-death syndrome ${ }^{6,10}$, and increased level of cotinine in follicular fluid ${ }^{12}$. Although the prevalence of female smokers is low in Middle-East countries, especially Iran, the high prevalence of smoking among men puts women at risk of SHS harms ${ }^{13}$. A study reported that more than half $(56.2 \%)$ of Iranian women were exposed to SHS during pregnancy ${ }^{14}$. The risk factors of SHS exposure for the pregnant women included poverty and illiteracy ${ }^{15}$, low level of education and unemployment ${ }^{7}$, inability of women to ask their husbands to quit smoking ${ }^{16}$, and existence of smokers in the family. Other factors examined include the belief of pregnant women that secondhand smoke harms the fetus ${ }^{14}$, lack of smoking laws at home ${ }^{17}$, lack of knowledge about smoking complications and dangers to family members ${ }^{18}$, perceived intensity and sensitivity of male smokers ${ }^{19}$, and finally male smokers not being informed about the negative effects of smoke on the fetus ${ }^{20}$. The WHO recommended that health care providers inform all the pregnant women about the complications of SHS exposure and strategies to avoid $\mathrm{SHS}^{21}$. In some countries of the developing world, women spent most of their time at home, so the main source of SHS is their husbands smoking ${ }^{22}$. Although the health training programs conducted for the pregnant women suggest that they avoid smoking and SHS, it remains a problem for Iranian pregnant women. Exposure to SHS is a significantly dangerous problem for the women in Middle-East countries and women in such communities are faced with various barriers to protecting their health and well-being ${ }^{23}$. The statistics showed higher rates of SHS exposure at home in countries with low and middle income ${ }^{24}$. Therefore, it is essential to encourage pregnant women to pursue preventative strategies ${ }^{23}$. In this regard, some studies investigated the decrease in SHS exposure on the basis of the Health Belief Model by changing the participants' health beliefs ${ }^{8,23}$. The Health Belief Model is based on behavioral patterns and includes individuals' vulnerability to diseases, effects of diseases on a person's life, as well as the effect of health performances in decreasing intensity and sensitivity ${ }^{25}$. Determination of the related factors and inequalities in SHS exposure can help to identify opportunities to reduce the inadequacies of health programs. The results of this study can help authorities to design and implement future educational interventions. Regarding the lack of studies on SHS exposure in Iran, we studied pregnant women's prevalence of exposure to SHS at home and the related factors.

\section{METHODS}

\section{Study design and population}

In this cross-sectional study, we selected 255 pregnant women who were referred to the Isfahan health centers from July to September 2018. The random sampling was conducted using the participant national codes registered in the electronic system of health centers by considering the maximum variation. Sample size was calculated according to a similar study 14 using the statistical indicators, 95\% confidence interval, (the SHS prevalence in pregnant women) $\mathrm{P}=60 \%$, and Standard Error 6\%. The inclusion criterion was that all married and pregnant women in all age groups are eligible for selection. The exclusion criteria included participants' unwillingness to participate in the research, active smoker women, presence of other sources of exposure such as other smokers at home, smokers at work, and women's active smoking, etc. The participants were first assured about the confidentiality of the information, oral consents were then obtained from them before the questionnaires were distributed to them. After the goals of the study were explained, individuals were asked to complete the questionnaire if they had the willingness and gave informed consent to participate in the study. Thus, only those who gave informed consent completed the questionnaire.

\section{Measures}

In order to collect the required information, we used a questionnaire that was designed by the research team, based on the Health Belief Model. The questionnaire used was self-administered.

The first section of the questionnaire included the participants' sociodemographic information: 
their age and husband's age, number of children, occupation and that of their husband, the family economic status, the gravid, gestational age, and type of pregnancy (wanted or unwanted).

The second section of the questionnaire was about the prevalence of exposure and included questions about the number of cigarettes smoked by the participant's husband per day, the number of cigarettes that the participant was exposed to and the duration of exposure per day. It also asked about the reaction of the participant's husband to her request about quitting smoking.

The third section of the questionnaire was about related factors affecting the prevalence of exposure, namely the participants' awareness and attitude towards SHS. In this section, 15 items were designed to investigate the women's knowledge about the complications of SHS on pregnancy and the fetus. Women needed to answer the questions using one of the available responses: 'Yes', 'No', and 'I do not know'. The attainable score in this part ranged from zero to 15; one point was given for the 'Yes' answer, whereas, the other response options got zero. Answers to questions 3 and 15 were scored reversely. Some examples of the questions asked in this part of the questionnaire include: 'What are some complications of exposure to SHS during pregnancy?' with some options being 'preterm labor' (item 1), 'higher probability of cesarean operation' (item 4), 'high-risk pregnancy' (item 5), etc. Another item was: 'What are the effects of SHS exposure for the fetus?' with possible answers being 'neonatal premature' (item 7), 'low birth weight' (item 9), ‘decreased growth' (item 13), 'probability of stillbirth' (item 14), etc.

The attitude section included the emotional dimension (4 questions), perceived susceptibility (10 questions), perceived severity (10 questions), and perceived environmental and personal barriers (12 questions). The items of these sections were answered on a 5-point Likert scale using the options: 'Completely disagree' (1), 'Disagree' (2), 'No idea' (3), 'Agree' (4), and 'Completely agree' (5).

The attitude-emotional dimension questions consisted of 4 questions with a score range of 4-20. The examples of questions in this section were: 'I prefer a place without the smoke of cigarettes', 'I do not like spending pregnancy in a smoke-filled environment', etc.

The perceived susceptibility section included 10 questions with a score range of 10-50. Examples of items in this section were statements such as: the pregnant women experienced preterm labor because they were exposed to smoke, the fetus showed low growth because of the mother's exposure to smoke, etc.

The perceived severity included 10 questions with a score range of 10-50. Examples of items in this section were statements such as: preterm labor has happened in many cases due to the exposure to smoke and the danger of low birth weight of the fetus is caused by smoke exposure, etc.

Moreover, the perceived environmental and personal barriers included 12 questions with a score range of 12-60. Examples of items in this part included the low level of education of husbands resulting in higher levels of smoking near their pregnant women and smoking husbands do not have free space to smoke, etc.

The content and visual validity of the questionnaire was measured using Content Validity Ratio, $\mathrm{GVR}=0.49$, Content Validity Index, CVI $=0.79$, and the comments received from the panel of experts. The panel of experts included eight professionals from health education, one expert from the health promotion sector, five professionals from reproductive health and one expert from psychology. The validity of the questionnaire was confirmed considering the values $\mathrm{CVR}=0.6$ and $\mathrm{CVI}=0.81$. The reliability of the tool was also calculated based on the internal consistency. Cronbach's alpha for 'Attitude emotional dimension', 'Perceived Susceptibility', 'Perceived Severity', and 'Perceived Barriers' was $0.81,0.91,0.92$, and 0.89 , respectively.

\section{Statistical analysis}

The data were analyzed using SPSS 18 and descriptive statistics were used to summarize and organize the data. Sociodemographic variables related to SHS were compared using chi-squared and Fischer nonparametric tests. The Mann-Whitney U test was used to compare mean scores of knowledge, attitude emotional dimension, perceived susceptibility, perceived severity and perceived barriers. The level of significance was set, a priori, at 0.05 , as the data did not have a normal distribution. 


\section{Ethical approval}

This study is part of a PhD dissertation in Health Education with ethical code IR.SSU.SPH. REC.1396.133. All the data were confidential and the results were presented for participants while oral consent was obtained from all participants.

\section{RESULTS}

Sociodemographic information is presented in Table 1. A total of 255 pregnant women were investigated with a mean age of $29.63 \pm 7.87$ years. The mean age of the participants' husbands was $33.40 \pm 5.14$ years. The results showed that of the 255 studied participants, 180 (70.6\%) husbands did not smoke, $59(23.1 \%)$ smoked, while $16(6.3 \%)$ of the husbands smoked but their wives were not exposed to SHS as

Table 1. The frequency distributions of the sociodemographic variables

\begin{tabular}{|c|c|c|c|}
\hline VARIABLES & & n $(\%)$ & Vean $=$ SD \\
\hline \multirow{2}{*}{$\begin{array}{l}\text { Age (years) } \\
\text { of woman }\end{array}$} & $\leq 30$ & $138(54.1)$ & \multirow{2}{*}{$29.63 \pm 4.78$} \\
\hline & $>30$ & $117(45.9)$ & \\
\hline \multirow{2}{*}{$\begin{array}{l}\text { Age (years) } \\
\text { of husband }\end{array}$} & $\leq 35$ & $169(66.3)$ & \multirow{2}{*}{$33.40 \pm 5.14$} \\
\hline & $>35$ & $86(33.7)$ & \\
\hline \multirow{3}{*}{$\begin{array}{l}\text { Number of } \\
\text { children }\end{array}$} & 0 & $141(53.3)$ & \multirow{3}{*}{ - } \\
\hline & 1 & 78 (30.6) & \\
\hline & $\geq 2$ & $36(14.1)$ & \\
\hline \multirow{3}{*}{$\begin{array}{l}\text { Education of } \\
\text { woman }\end{array}$} & Reading and writing & $47(18.4)$ & \multirow{3}{*}{ - } \\
\hline & High school diploma & $109(42.7)$ & \\
\hline & $\begin{array}{c}\text { Bachelor degree and } \\
\text { higher }\end{array}$ & 99 (38.8) & \\
\hline \multirow{3}{*}{$\begin{array}{l}\text { Education of } \\
\text { husband }\end{array}$} & Reading and writing & $63(24.7)$ & \multirow{3}{*}{ - } \\
\hline & High school diploma & $123(48.2)$ & \\
\hline & $\begin{array}{c}\text { Bachelor degree and } \\
\text { higher }\end{array}$ & $69(27.1)$ & \\
\hline \multirow{2}{*}{$\begin{array}{l}\text { Occupation } \\
\text { of woman }\end{array}$} & Housewife & $219(58.9)$ & \multirow{2}{*}{ - } \\
\hline & Employed & $36(14.1)$ & \\
\hline \multirow{4}{*}{$\begin{array}{l}\text { Occupation } \\
\text { of husband }\end{array}$} & Government employed & $52(20.4)$ & \multirow{4}{*}{ - } \\
\hline & Self-employed & $140(54.9)$ & \\
\hline & Laborer & $58(22.7)$ & \\
\hline & Jobless & $5(2)$ & \\
\hline \multirow{3}{*}{ Income level } & Poor & $22(8.6)$ & \multirow{3}{*}{-} \\
\hline & Moderate & $209(82)$ & \\
\hline & Good & $24(9.4)$ & \\
\hline \multirow{2}{*}{ Pregnancy } & Planned pregnancy & 214 (83.9) & \multirow{2}{*}{-} \\
\hline & Unplanned pregnancy & 41 (16.1) & \\
\hline \multirow{2}{*}{ Gravid } & 1 & $147(57.6)$ & \multirow{2}{*}{ - } \\
\hline & $\geq 2$ & $108(42.4)$ & \\
\hline \multirow{3}{*}{$\begin{array}{l}\text { Month of } \\
\text { pregnancy }\end{array}$} & First trimester & 48 (18.8) & \multirow{3}{*}{-} \\
\hline & Second trimester & $117(45.9)$ & \\
\hline & Third trimester & $90(35.3)$ & \\
\hline
\end{tabular}

the husband never smoked at home or near the wife in order to protect her health and that of the child.

About $54.7 \%$ of husbands smoked 2-5 cigarettes per day and about $48 \%$ of pregnant women were exposed to 2-5 cigarettes per day. However, most women were exposed to SHS for less than one hour per day. Considering the results of Table 2, the majority of women selected the options 'He goes to another place' and 'He puts out the cigarette' in responding to the question regarding the husband's reaction after being asked to quit smoking.

The age of husbands $(p=0.041)$, the education level of husbands $(p=0.005)$ and the education level of pregnant women $(p=0.002)$, the employment status of husbands $(p=0.010)$, and the type of pregnancy $(p=0.010)$ had a significant association with the proportion exposed. The older age of husbands, lower education level of husbands and women, unwanted pregnancy, and unemployment of husbands, resulted in increased exposure to smoke. No significant difference was observed in sociodemographic characteristics of the participants $(p>0.05)$. The proportion of exposure was also higher among unemployed women of younger age, more than two children, and weak economic situation (Table 3 ).

Table 2. The frequency distributions of the responses to questions about the exposure to cigarette smoke

\begin{tabular}{|c|c|c|c|}
\hline RESPONSES & & n $\left({ }^{\circ} \%\right)$ & Vean \pm SD \\
\hline \multirow{4}{*}{$\begin{array}{l}\text { Number of } \\
\text { cigarettes } \\
\text { consumed by } \\
\text { husband per } \\
\text { day }\end{array}$} & 1 & $10(13.3)$ & \multirow{4}{*}{$\begin{array}{c}5.12 \pm 4.26 \\
1-20 \\
\text { cigarettes }\end{array}$} \\
\hline & $2-5$ & $41(54.7)$ & \\
\hline & $6-10$ & 19 (25.3) & \\
\hline & $>10$ & $5(6.7)$ & \\
\hline \multirow{5}{*}{$\begin{array}{l}\text { The number } \\
\text { of cigarettes } \\
\text { exposed to } \\
\text { their smoke } \\
\text { per day }\end{array}$} & 0 & $16(21.3)$ & \multirow{5}{*}{$\begin{array}{c}3.29 \pm 3.91 \\
0-20 \\
\text { cigarettes }\end{array}$} \\
\hline & 1 & $12(16)$ & \\
\hline & $2-5$ & $36(48)$ & \\
\hline & $6-10$ & $9(12)$ & \\
\hline & $>10$ & $2(2.7)$ & \\
\hline \multirow{4}{*}{$\begin{array}{l}\text { Hours of } \\
\text { exposure } \\
\text { to cigarette } \\
\text { smoke } \\
\text { per day }\end{array}$} & $\leq 1$ & $34(45.3)$ & \multirow{4}{*}{ - } \\
\hline & $1-2$ & $21(28)$ & \\
\hline & $>2$ & $4(5.3)$ & \\
\hline & Not exposed & $16(21.3)$ & \\
\hline \multirow{5}{*}{$\begin{array}{l}\text { Husband's } \\
\text { reaction to } \\
\text { your request } \\
\text { to quit } \\
\text { smoking? }\end{array}$} & Put out the cigarette & $24(32)$ & \multirow{5}{*}{ - } \\
\hline & Opened the window & $7(9.3)$ & \\
\hline & Went to another place & 25 (33.3) & \\
\hline & $\begin{array}{l}\text { Requested that I go to } \\
\text { another place }\end{array}$ & $6(8)$ & \\
\hline & Indifference & $13(17.3)$ & \\
\hline
\end{tabular}


Table 3. The comparison of sociodemographic variables based on exposure of pregnant women to cigarette smoke

\begin{tabular}{|c|c|c|c|c|c|}
\hline VARIABLES & & $\begin{array}{c}\text { Exposed } \\
\text { In (\%) }\end{array}$ & $\begin{array}{l}\text { Not exposed } \\
\text { In (\%) }\end{array}$ & $\begin{array}{l}\text { Total } \\
\text { n (\%) }\end{array}$ & p \\
\hline \multirow{2}{*}{ Age (years) of woman } & $\leq 30$ & $32(23.2)$ & 106 (76.8) & $138(100)$ & \multirow{2}{*}{0.552} \\
\hline & $>30$ & $27(23.1)$ & 90 (76.9) & $117(100)$ & \\
\hline \multirow{2}{*}{ Age (years) of husband } & $\leq 35$ & $33(19.5)$ & $136(80.5)$ & $169(100)$ & \multirow{2}{*}{$0.041^{* *}$} \\
\hline & $>35$ & $26(30.2)$ & $60(69.8)$ & $86(100)$ & \\
\hline \multirow{3}{*}{ Education of woman } & Reading and writing & $17(36.2)$ & $30(63.8)$ & $47(100)$ & \multirow{3}{*}{$0.005^{*}$} \\
\hline & High school diploma & $29(26.6)$ & $80(73.4)$ & $109(100)$ & \\
\hline & Bachelor degree and higher & $13(13.1)$ & 86 (86.9) & $99(100)$ & \\
\hline \multirow{3}{*}{ Education of husband } & Reading and writing & $24(38.1)$ & $39(61.9)$ & $63(100)$ & \multirow{3}{*}{$0.002^{*}$} \\
\hline & High school diploma & $26(21.1)$ & $97(78.9)$ & $123(100)$ & \\
\hline & Bachelor degree and higher & $9(13)$ & $60(87)$ & $69(100)$ & \\
\hline \multirow{3}{*}{ Occupation of husband } & Government employed & $4(7.7)$ & $48(92.3)$ & $52(100)$ & \multirow{3}{*}{$0.010^{*}$} \\
\hline & Self-employed & $36(25.7)$ & $104(74.3)$ & $140(100)$ & \\
\hline & Laborer and unemployed & $19(30.2)$ & $44(69.8)$ & $63(100)$ & \\
\hline \multirow{2}{*}{ Occupation of woman } & Housewife & $52(23.7)$ & $167(76.3)$ & $219(100)$ & \multirow{2}{*}{0.371} \\
\hline & Employed & 7 (19.4) & $29(80.6)$ & $36(100)$ & \\
\hline \multirow{2}{*}{ Pregnancy } & Planned pregnancy & $43(20.1)$ & 171 (79.9) & $214(100)$ & \multirow{2}{*}{$0.010^{* *}$} \\
\hline & Unplanned pregnancy & $16(39)$ & $25(61)$ & $41(100)$ & \\
\hline \multirow{3}{*}{ Number of children } & 0 & $31(22)$ & $110(78)$ & $141(100)$ & \multirow{3}{*}{0.523} \\
\hline & 1 & $17(21.8)$ & $61(78.2)$ & $78(100)$ & \\
\hline & $\geq 2$ & $11(30.6)$ & $25(69.4)$ & $36(100)$ & \\
\hline \multirow{3}{*}{ Income level } & Poor & $9(40.9)$ & $13(59.1)$ & $22(100)$ & \multirow{3}{*}{0.099} \\
\hline & Moderate & $46(22)$ & $163(78)$ & $209(100)$ & \\
\hline & Good & $4(16.7)$ & $20(83.3)$ & $24(100)$ & \\
\hline
\end{tabular}

${ }^{*}$ Chi-squared test. ${ }^{* *}$ Fisher's exact test.

Table 4. The comparison of mean score of structures based on exposure of pregnant women to cigarette smoke

$\begin{array}{lccc}\text { STIRLCTURES } & \text { Evposed } & \text { Vean SD } & \text { p } \\ \text { Knowledge } & \text { Yes } & 7.62 \pm 4.53 & 0.049^{*} \\ \text { Attitude-emotional } & \text { No } & 8.89 \pm 4.04 & \\ \text { dimension } & \text { Yes } & 15.52 \pm 3.95 & 0.000^{*} \\ \text { Perceived susceptibility } & \text { No } & 17.78 \pm 2.84 & \\ & \text { Yes } & 35.66 \pm 5.15 & 0.000^{*} \\ \text { Perceived severity } & \text { No } & 38.58 \pm 6.09 & \\ & \text { No } & 34.37 \pm 6.20 & 0.000^{*} \\ \text { Perceived barriers } & \text { Yes } & 41.94 \pm 8.14 & \\ & \text { No } & 42.11 \pm 8.38 & 0.449\end{array}$

* Mann-Whitney test

The mean scores of knowledge $(\mathrm{p}=0.049)$, attitude-emotional dimension $(\mathrm{p}=0.000)$, perceived susceptibility $(p=0.000)$, and perceived severity $(\mathrm{p}=0.000)$ were significantly different between the exposed and non-exposed participants; the mean scores of knowledge, attitude-emotional dimension, perceived susceptibility, and perceived severity, were lower in the exposed group. However, the mean scores of the perceived barrier were not significantly different between the two studied groups $(\mathrm{p}=0.449)$ (Table 4$)$.

\section{DISCUSSION}

Evaluation of the exposure to cigarette smoke and its avoidance strategies is a crucial part of the pregnancy care programs ${ }^{9}$. To the best of our knowledge, this study was the first conducted in Iran to determine the prevalence of exposure to SHS in pregnant women and the related factors. The findings of this study on the risk factors of SHS exposure and the controversies of this area can help authorities to identify opportunities for reducing the existing inequalities. They are also recommended to conduct educational interventions in order to improve the knowledge of pregnant women and their families of the harms of SHS.

In our study, we found that $23.1 \%$ of pregnant women were exposed to SHS from their husband's cigarettes, which is a relatively low rate in comparison with the level of exposure of Iranian pregnant women to secondhand smoke (56\%) 
according to the results of the study conducted by Baheiraei et al. ${ }^{14}$. However, this rate is higher or similar to the prevalence of exposure of other countries. A review study suggested that the rate of SHS exposure at home ranged from $17-73$ per cent in different countries ${ }^{17}$. According to the results of the studies conducted by Goel et al. ${ }^{9}$ in India, Alghamdi et al. ${ }^{7}$ Wahabi et al. ${ }^{26}$ in Saudi Arabia, and Aurrekoetxea et al. ${ }^{27}$ in Spain, a total of 24, 24, 37 and 24.7 per cent of the pregnant women were exposed to smoke, respectively. The husband's amount of smoking was reported as the main predictive factor for the SHS prevalence of exposure of pregnant women at home ${ }^{22}$. Sarraf-Zadegan et al. ${ }^{13}$ studied the smoking rate of men in Isfahan in Iran $(18.7 \%)$ and reported that it was lower than national rates. Considering the above study and the low level of smoking in men in the region of the study compared to the national level, the lower exposure of pregnant women to secondhand smoke from the husband's cigarettes can, therefore, be justified in this study. Although most women were concerned about the unfavorable effects of cigarettes on their family members, they preferred to keep the smoker husbands in the house. They believed that the physical presence of husbands with the family and in the home was necessary ${ }^{28}$. These beliefs, arising from cultural and social backgrounds, created the situation for the family member's higher SHS exposure.

The most likely number of daily cigarettes to which the pregnant women were exposed was about 2-5 for less than one hour. Alghamdi et al. ${ }^{7}$ in Saudi Arabia reported that the exposure time to smoke was less than one hour for most of the women. Loke et al. ${ }^{22}$ reported that the women living with smoking husbands were exposed to cigarette smoke for about 4.2 hours per day. The rate of cigarette smoking in men per day is directly correlated with their level of dependency ${ }^{29}$. Therefore, the dependency of husbands results in a high prevalence of exposure of pregnant women to smoke. Patriarchy and inability of women to go against their husband's smoking habit were reported as factors by Mao et al. ${ }^{30}$. However, in the current study, the positive response of husbands in avoiding smoking or leaving the shared environment demonstrated their concern about the health of the wife and child. The pregnancy of women can provide a good opportunity for the husbands to quit smoking or reduce it.

The pregnant woman's age had no significant association with the prevalence of exposure whereas the husband's age had a significant association. The prevalence of exposure was higher in women living with older husbands. However, Alghamdi et al. ${ }^{7}$ in Saudi Arabia and Lee et al. ${ }^{31}$ in China found a significant relationship between the age of pregnant women and the prevalence of exposure to SHS. Moreover, Aurrekoetxea et al. ${ }^{27}$ in Spain indicated that young women had a high level of prevalence of exposure to SHS. Quitting smoking was found to be difficult when the rate of smoking increased with age ${ }^{32}$ and when men were more depended on the smoking ${ }^{29}$.

The education levels of pregnant women and their husbands were significantly related to the prevalence of exposure; exposure increased with lower education level. Alghamdi et al. ${ }^{7}$ and Wahabi et al. ${ }^{26}$ in Saudi Arabia, Aurrekoetxea et al. ${ }^{27}$ in Spain, Lee et al. ${ }^{31}$ in China, Kelly et al. ${ }^{15}$ in India, and Nazar et al. ${ }^{24}$ in 15 countries with low and middle income, indicated lower education level was a predictor of high prevalence of exposure. Moreover, there was a direct and significant relationship between weak awareness of the harms of exposure to SHS and lowlevel education, as well as unemployment or lowincome jobs ${ }^{33}$, a factor that increased the possibility of being home and making the pregnant woman more susceptible to SHS exposure.

Although the employment status of women did not show any significant relationship with the prevalence of exposure in the present study, we found that housewives had a higher prevalence of exposure than the employed women. The women with unemployed husbands reported higher prevalence of exposure. The studies of Alghamdi et al. ${ }^{7}$ and Wahabi et al. ${ }^{26}$ in Saudi Arabia confirm the above findings. Jobless and laborer husbands (because of unknown employment condition) increased the possibility of being home with their housewives, resulting in higher exposure to SHS.

Unwanted or wanted pregnancy also had a significant association with SHS prevalence of exposure; the women who experienced unwanted pregnancies had higher exposure. The association of unwanted pregnancy with low education level and social factors has been shown ${ }^{34}$; hence, an unwanted pregnancy can be considered a predictor of higher 
prevalence of exposure to SHS requiring special care for the child.

We observed no relationship between the number of children and the prevalence of exposure to SHS; however, the prevalence of exposure in women who had more than two children was higher than in women with fewer children. Wahabi et al. ${ }^{26}$ in Saudi Arabia and Aurrekoetxea et al. ${ }^{27}$ in Spain indicated that women with fewer pregnancies had a lower prevalence of exposure. The results of these studies are aligned with our current (nonsignificant) patterns. The relationship between low education level and the number of children was also confirmed $^{35}$, which can justify the higher prevalence of exposure of women with more than two children.

In addition, we found that the economic condition had no significant relationship with the prevalence of exposure; however, the women who had weaker economic conditions reported higher prevalence of exposure. Kelly et al. ${ }^{15}$ indicated that poverty was a risk factor for SHS exposure for women and children $^{15}$. Alghamdi et al. ${ }^{7}$ in Saudi Arabia and Aurrekoetxea et al. ${ }^{27}$ in Spain showed that the families of lower social class experienced higher exposure to SHS. Yang et al. ${ }^{36}$ studied rural women in China and found that despite the existence of a smoking prohibition law for homes, they were exposed to smoke. Considering the proved relationship between low levels of education and awareness ${ }^{15}$, education level can be considered as a predictor of SHS exposure rate.

In this regard, we found that the mean score of knowledge was lower in pregnant women exposed to SHS than for the non-exposed group. Passey et al. ${ }^{37}$ indicated that lack of knowledge and awareness acted as a barrier to avoiding SHS exposure. Having knowledge about the hazards of SHS motivated them to change their situation and improve their health. Yang et al. ${ }^{36}$ carried out a study in China and reported that rural women, who were not provided with enough knowledge about SHS had high rates of exposure. In another study, the lack of knowledge about SHS exposure complications on family members and fetus was considered as an important risk factor for the prevalence of exposure ${ }^{18-20}$.

Vivilaki et al. ${ }^{38}$ in Greece indicated that awareness about the health problem for the fetus and attitude to smoke during pregnancy were the main factors in pregnant smoker women. Bahiraii et al. ${ }^{14}$ reported that presence of a smoking individual and false beliefs of pregnant women about the effects of smoke on the health of the fetus could be important elements to consider in order to improve the prevalence of exposure. Kazemi et al. ${ }^{23}$ in Isfahan reported that the training supposed to be effective in increasing the health beliefs and decreasing the prevalence of exposure seem inadequate to avoid smoke at home.

From the findings of the present study, it is clear that we need to increase the knowledge of pregnant women about the effects of SHS during pregnancy. The health care providers are also recommended to follow this idea seriously. The lack of proper strategies to decrease the prevalence of exposure indicate weak knowledge. However, several strategies have been recommended to have a smokefree home: ask the smoking people to smoke in another room, outdoors or near an open window; use a ventilator; and keep a distance from the smokers ${ }^{37}$.

\section{Limitations}

One limitation of this study was the self-reporting method of data collection; this method is affected by memory deficiencies. We suggest other researchers conduct studies using the cotinine index to confirm the results. Another limitation of this study was that we only measured the husbands' smoking status and did not investigate other sources of exposure, such as presence of other smokers in the home, smokers at work, and women's active smoking. The other limitation was the low participation rate and avoidance of women in talking about the smoking habits of their husbands. In our investigations throughout the participants' profiles available at the health care centers, we found many blank spaces in response to the questions about the smoking status of husbands in the family, which was considered as another limitation. This deficiency should be considered while updating the profiles in the health care centers. Despite the limitations, our findings are valuable.

\section{CONCLUSIONS}

This study reported that 23.1 per cent of pregnant women were exposed to SHS at home from their husbands' smoking. Furthermore, the knowledge and attitude scores of women about smoking were low and 
showed an unfavorable condition. Unemployment and older age of husbands, low levels of education, and unwanted pregnancies were considered as risk factors for the women's higher prevalence of exposure. Therefore, we recommend that health care providers plan and implement educational training programs regarding these risk factors for the pregnant women and their husbands. Training programs provided should increase the women's awareness, change their attitudes, increase their ability to protect themselves and their child against smoke, and help them to have a smoke-free home.

\section{REFERENCES}

1. World Health Organization. Gender, Health, Tobacco and Equity. 2011. http://www.who.int/tobacco/publications/ gender/gender_tobacco_2010.pdf. Accessed October 1, 2018.

2. World Health Organization. WHO report on the global tobacco epidemic, 2013: Enforcing bans on tobacco advertising, promotion and sponsorship. Geneva: World Health Organization; 2013. http://www.who.int/tobacco/ global_report/2013/en. Accessed October 1, 2018.

3. Öberg M, Jaakkola MS, Woodward A, et al. Worldwide burden of disease from exposure to second-hand smoke: a retrospective analysis of data from 192 countries. Lancet. 2011;377(9760):139-146. doi:10.1016/s0140-6736(10)61388-8

4. World Health Organization. Tobacco Free Initiative (TFI): Second-hand tobacco smoke. http://www.who. int/tobacco/research/secondhand_smoke/en/. Accessed October 1, 2018.

5. Centers for Disease Control and Prevention. Smoking and Tobacco use: Secondhand Smoke (SHS) Facts. https:// www.cdc.gov/tobacco/data_statistics/fact_sheets/ secondhand_smoke/general_facts/. Accessed October 1, 2018.

6. Alemán A, Morello P, Colomar M, et al. Brief Counseling on Secondhand Smoke Exposure in Pregnant Women in Argentina and Uruguay. Int J Environ Res Public Health. 2016;14(1):28. doi:10.3390/ijerph14010028

7. Alghamdi AS, Jokhadar HF, Alghamdi IM, et al. Socioeconomic Determinants of Exposure to Secondhand Smoke Among Pregnant Women. International Journal Of Womens Health And Reproduction Sciences. 2016;4(2):59-63. doi:10.15296/ijwhr.2016.14

8. Chi YC, Sha F, Yip PS, Chen JL, Chen YY. Randomized comparison of group versus individual educational interventions for pregnant women to reduce their secondhand smoke exposure. Medicine. 2016;95(40):17. doi: $10.1097 / \mathrm{md} .0000000000005072$

9. Goel P, Radotra A, Singh I, Aggarwal A, Dua D. Effects of passive smoking on outcome in pregnancy. J Postgrad
Med. 2004;50(1):12-16. http://www.jpgmonline.com/ article.asp?issn $=0022-3859 ;$ year $=2004 ;$ volume $=50$;issue $=1 ;$ spage $=12 ;$ epage $=16 ;$ aulast $=$ Goel . Accessed October $1,2018$.

10. Mojibyan M, Karimi M, Bidaki R, Rafiee P, Zare A. Exposure to second-hand smoke during pregnancy and preterm delivery. Int J High Risk Behav Addict. 2013;1(4):149-153. doi:10.5812/ijhrba.7630

11. Amasha HA, Jaradeh MS. Effect of active and passive smoking during pregnancy on its outcomes. Health Science Journal. 2012;6(2):335-352. http://www.hsj.gr/ medicine/effect-of-active-and-passive-smoking-duringpregnancy-on-its-outcomes.pdf. Accessed October 1, 2018.

12. Kazemi A, Ramezanzadeh F, Esfahani MHN, et al. Impact of environmental tobacco smoke exposure in women on oxidative stress in the antral follicle and assisted reproduction outcomes. J Res Med Sci. 2013;18(8):688694. https://www.ncbi.nlm.nih.gov/pmc/articles/ PMC3872608/. Accessed October 1, 2018.

13. Sarraf-Zadegan N, Boshtam M, Shahrokhi S, et al. Tobacco use among Iranian men, women and adolescents. Eur J Public Health. 2004;14(1):76-78. doi:10.1093/eurpub/14.1.76

14. Bahiraii A, Faghihi RS, Mirmohammad AM, Kazem, NA. Predictors of home smoking ban in households in pregnant women. Payesh. 2012;11(4):511-517. https:// www.sid.ir/en/journal/ViewPaper.aspx?ID=274492. Accessed October 1, 2018.

15. Kelly PJ, Goudar SS, Chakraborty H, et al. Pregnant women and children's exposure to tobacco and solid fuel smoke in southwestern India. J Matern Fetal Neonatal Med. 2010;24(7):973-977. doi:10.3109/14767058.2010.537411

16. Nichter M, Padmajam S, Nichter M, et al. Developing a smoke free homes initiative in Kerala, India. BMC public health. 2015;15(1):480. doi:10.1186/s12889-015-1815-1

17. Zhang L, Hsia J, Tu X, et al. Exposure to Secondhand Tobacco Smoke and Interventions Among Pregnant Women in China: A Systematic Review. Prev Chronic Dis. 2015;12(35):1-11. doi:10.5888/pcd12.140377

18. Ma SJ, Wang JF, Mei CZ, Xu XF, Yang GH. Passive smoking in China: contributing factors and areas for future interventions. Biomed Environ Sci. 2007;20(5):420425. https://www.ncbi.nlm.nih.gov/pubmed/18188996. Accessed October 1, 2018.

19. Sahebi Z, Kazemi A, Loripoor Parizi M. The relationship between husbands' health belief and environment tobacco smoke exposure among their pregnant wife. J Matern Fetal Neonatal Med. 2016;30(7):830-833. doi:10.1080/14767058.2016.1188071

20. Wakefield M, Reid Y, Roberts L,Mullins R, Gillies P. Smoking and smoking cessation among men whose partners are pregnant: a qualitative study. Soc Sci Med. 1998;47(5):657664. doi:10.1016/s0277-9536(98)00142-7 
21. World Health Organization. WHO recommendations for the prevention and management of tobacco use and second-hand smoke exposure in pregnancy. Geneva: World Health Organization; 2013. http:// www.who.int/tobacco/publications/pregnancy/ guidelinestobaccosmokeexposure/en/index.html. Accessed October 1, 2018.

22. Loke AY, Lam TH, Pan SC, Li SY, Gao XJ, Song YY. Exposure to and actions against passive smoking in non-smoking pregnant women in Guangzhou, China. Acta Obstet Gynecol Scand. 2000;79(11):947-952. doi:10.1034/j.1600-0412.2000.079011947.x

23. Kazemi A, Ehsanpour S, Nekoei-Zahraei NS. A randomized trial to promote health belief and to reduce environmental tobacco smoke exposure in pregnant women. Health Educ Res. 2012;27(1):151-159. doi:10.1093/her/cyr102

24. Nazar GP, Lee JT, Arora M, Millett C. Socioeconomic inequalities in secondhand smoke exposure at home and at work in 15 low-and middle-income countries. Nicotine Tob Res. 2015;18(5):1230-1239. doi:10.1093/ntr/ntv261

25. Glanz KA, Rimer BA, Viswanth K. Health behavior and health education theory, research and practice. 4th ed. San Farancisco: Josey-Bass Publisher; 2008: 8-30.

26. Wahabi HA, Alzeidan RA, Fayed AA, Mandil A, AlShaikh G, Esmaeil SA. Effects of secondhand smoke on the birth weight of term infants and the demographic profile of Saudi exposed women. BMC Public Health. 2013;13(1):341. doi:10.1186/1471-2458-13-341

27. Aurrekoetxea JJ, Murcia M, Rebagliato M, et al. Factors associated with second-hand smoke exposure in nonsmoking pregnant women in Spain: self-reported exposure and urinary cotinine levels. Sci Total Environ. 2014;470471:1189-1196. doi:10.1016/j.scitotenv.2013.10.110

28. Mao A, Bristow K, Robinson J. Caught in a dilemma: why do non-smoking women in China support the smoking behaviors of men in their families? Health Educ Res. 2013;28(1):153-164. doi:10.1093/her/cys078

29. Meamar R, Maracy M, Bahonar A, et al. Association of Sociodemographic Characteristic with Factors Related to Cigarette Abstinence in Isfahan Smokers, Iran. Journal of Isfahan Medical School. 2014;32(297):1-13.

30. Mao A. Getting over the patriarchal barriers: women's management of men's smoking in Chinese families. Health Educ Res. 2015;30(1):13-23. doi:10.1093/her/cyu019

31. Lee NL, Samet JM, Yang G, et al. Prenatal secondhand smoke exposure and infant birth weight in China. Int J Environ Res Public Health. 2012;9(10):3398-3420. doi:10.3390/ijerph9103398

32. Burns DM, Major JM, Shanks TG. Changes in number of cigarettes smoked per day: cross-sectional and birth cohort analyses using NHIS. In: Bethesa, MD. Those who continue to smoke: Is achieving abstinence harder and do we need to change our interventions. Smoking and Tobacco Control Monograph No 15. Department of Health and Human Services, Public Health Service, National Institutes of Health, National Cancer Institute, NIH Publication; 2003:83-97. https://cancercontrol. cancer.gov/brp/tcrb/monographs/15/monograph15.pdf. Accessed October 1, 2018.

33. Mirowsky J. Education, social status, and health. New York, Routledge; 2003.

34. Araban M, Khoushbin A, Bokaei M, et al. Unwanted Pregnancy And Related Factors. Iran J Reprod Med. 2009;7(2):1-10.

35. Mobasheri M, Alidosti M, Sorshajani S, Khosravi F, Khalafian P, Jalilian M. Determination of the most important factors influencing the fertility patterns of single child and without child families in Shahr-ekord city in 2013. Scientific Journal of Ilam University of Medical Sciences. 2013;21(6):63-70. http://sjimu. medilam.ac.ir/article-1-1435-en.html. Accessed October $1,2018$.

36. Yang L, Tong EK, Mao Z, Hu TW. Exposure to secondhand smoke and associated factors among nonsmoking pregnant women with smoking husbands in Sichuan province, China. Acta Obstet Gynecol Scand. 2010;89(4):549-557. doi:10.3109/00016341003713851

37. Passey ME, Longman JM, Robinson J, Wiggers J, Jones LL. Smoke-free homes: what are the barriers, motivators and enablers? A qualitative systematic review and thematic synthesis. BMJ Open. 2017;6(3):e010260. doi:10.1136/bmjopen-2015-010260

38. Vivilaki VG, Diamanti A, Tzeli M, et al. Exposure to active and passive smoking among Greek pregnant women. Tob Induc Dis. 2016;14(1):12. doi:10.1186/s12971-016-0077-8

ACKNOWLEDGEMENTS

This study is part of a PhD thesis in Health Education with ethical code IR.SSU.SPH.REC.1396.133 at the Shahid Sadoughi University of Medical Sciences. The authors would like to express their gratitude and appreciation to the President of the Faculty of Health of Shahid Sadoughi University, to the President of the Faculty of Nursing and Midwifery of the Isfahan University of Medical Science, and to the pregnant women who participated in the study.

CONFLICTS OF INTEREST

The authors have completed and submitted the ICMJE Form for Disclosure of Potential Conflicts of Interest and none was reported.

FUNDING

The present article was financially supported by the School of Health, Shahid Sadoughi University of Medical Sciences, Yazd, Iran.

PROVENANCE AND PEER REVIEW

Not commissioned; externally peer reviewed. 